\title{
Did the Climate Forecast System Anticipate the 2015 Caribbean Drought?
}

\author{
PAul W. Miller \\ Coastal Meteorology Lab, Department of Oceanography and Coastal Sciences, Louisiana State University, Baton \\ Rouge, Louisiana \\ CRAIG A. RAMSEYER \\ Department of Geography, Virginia Tech, Blacksburg, Virginia
}

(Manuscript received 9 December 2019, in final form 17 April 2020)

\begin{abstract}
In groundwater-limited settings, such as Puerto Rico and other Caribbean islands, societal, ecological, and agricultural water needs depend on regular rainfall. Though long-range numerical weather predication models explicitly predict precipitation, such quantitative precipitation forecasts (QPF) critically failed to detect the historic 2015 Caribbean drought. Consequently, this work examines the feasibility of developing a drought early warning tool using the Gálvez-Davison index (GDI), a tropical convective potential index, derived from the Climate Forecast System, version 2 (CFSv2). Drought forecasts are focused on Puerto Rico's early rainfall season (ERS; April-July), which is susceptible to intrusions of strongly stable Saharan air and represents the largest source of hydroclimatic variability for the island. A fully coupled atmosphere-oceanland model, the CFSv2 can plausibly detect the transatlantic advection of low-GDI Saharan air with multimonth lead times. The mean ERS GDI is calculated from semidaily CFSv2 forecasts beginning 1 January of each year between 2012 and 2018 and monitored as the initialization approaches 1 April. The CFSv2 demonstrates a broad region of statistically significant correlations with observed GDI across the eastern Caribbean up to 30 days prior to the ERS. During 2015, the CFSv2 forecast a low-GDI tongue extending across the Atlantic toward the Caribbean with 60-90 days lead time and placed Puerto Rico's 2015 ERS beneath the 15th percentile of all 1982-2018 ERS forecasts with up to 30 days lead time. A preliminary GDIbased QPF tool tested herein is a statistically significant improvement over climatology for the driest years.
\end{abstract}

\section{Introduction}

In 2015, the U.S. commonwealth of Puerto Rico (PR) was struck by a historic, record-breaking drought. Though the year began with relatively normal precipitation, rainfall deficits quickly accumulated during April and May, which traditionally mark the onset of the early rainfall season (ERS; April-July). By its conclusion, the 2015 ERS observed the driest such 4-month period ever recorded at Luis Muñoz Marín International Airport in San Juan, PR, surpassing even the drought of record, 1993, in severity during the ERS. Beyond precipitation, the 2015 drought was associated with historically low discharges in the Río Piedras watershed, acute reductions in soil moisture, and mandatory water rationing (NOAA/NCEI 2016; O’Connell et al. 2018; Ramírez et al. 2018). A particularly unique aspect of the 2015 drought is that it was most severe during Puerto Rico's

Corresponding author: Paul W. Miller, pmiller1@lsu.edu
ERS, and subsequent hydroclimatic analyses by Miller et al. (2019a) have since shown that the ERS contributes the most variability to the annual precipitation outcome. Effectively, wetter (drier) ERSs are associated with pluvial (drought) years, a statistically significant relationship that is not present during other seasons.

Though media outlets opted to attribute the 2015 drought to the strong ongoing El Niño event, subsequent research has scrutinized the relationship between ENSO and Caribbean drought (Torres-Valcárcel 2018). In contrast, Mote et al. (2017) proposed that the drought was associated with an anomalously active Saharan air layer (SAL), a tongue of hot, dry, dust-laden air extending from Saharan Africa, across the Atlantic, and sometimes into the Caribbean. Though prior research has linked ENSO to North African dust emission (DeFlorio et al. 2016), the presence of the SAL directly suppresses convective activity by creating a warm, stable pocket that prevents nascent cumulus updrafts from maturing into deep moist convective storms. The high dust content of 


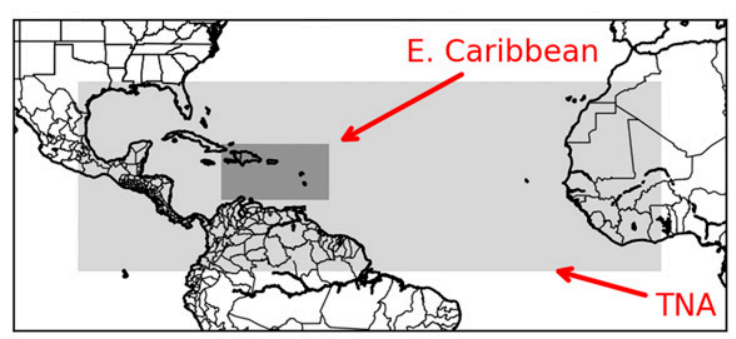

(A)

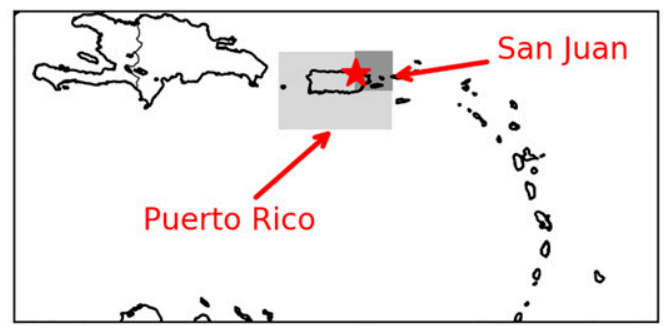

(B)
(C)

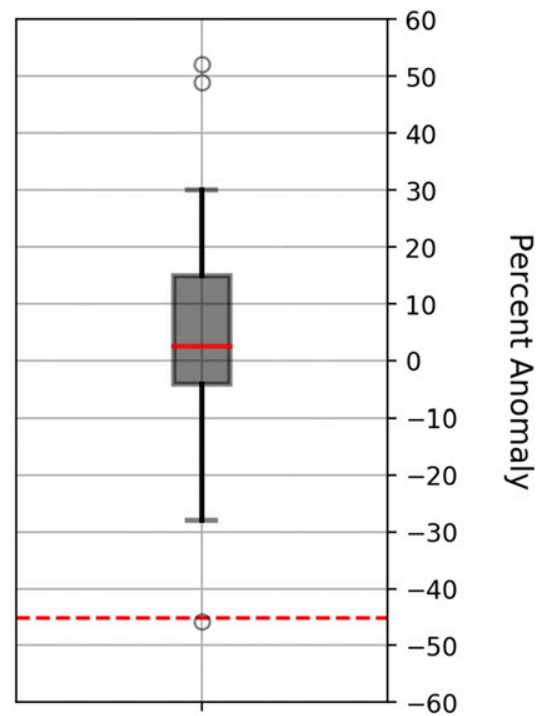

CFS 2015 ERS QPF

(0-30 days lead time)

FIG. 1. The four subdomains for which CFS GDI predictions are averaged and analyzed as well as the distribution of CFS QPF preceding the 2015 ERS drought. (a) View of the largest two domains: the tropical North Atlantic (TNA) and the eastern Caribbean. (b) An inset view of the smallest two domains: Puerto Rico and San Juan with the TJSJ radiosonde site marked by a red star. The inset viewing window in (b) corresponds to the "E. Caribbean" domain in (a). (c) The distribution of CFS QPFs averaged over cells containing Puerto Rico predicted during March 2015 (odd number days only), the month leading up to the start of the ERS. The red dashed line indicates the observed 2015 ERS precipitation anomaly.

the layer further alters convective growth through the direct (e.g., Yu et al. 2006) and indirect aerosol effect (e.g., Rosenfeld and Gutman 1994). The former references aerosol absorption of incoming solar radiation, further warming the layer, whereas the latter describes the microphysical consequences of the dust acting as abundant cloud condensation nuclei. Though the SAL is a normal part of the tropical North Atlantic and Caribbean climate system, dust concentrations at Miami, Florida, and Barbados typically are highest in June or July (Zuidema et al. 2019). However, in 2015, strong SAL intrusions were first documented in April and continued for several months (Mote et al. 2017; Zuidema et al. 2019).

Whereas Mote et al. (2017) examined a synoptic mechanism for the 2015 drought, recent work by Hosannah et al. (2019) investigated local-scale processes associated with Puerto Rico convective rainfall. Observations showed spatially varying precipitation anomalies across the island during the 2015 drought, which the authors attributed to locally modulated manifestations of the synoptic forcing. For example, in western Puerto Rico, sea breeze convergence and orographic uplift were found to reduce the effect of dust on rainfall. However, eastern Puerto Rico, which receives the most direct influence from SAL, was more sensitive to dust-rainfall influences.
Though large-scale synoptic mechanisms, such as the SAL, were clearly instrumental in the development of the 2015 Caribbean drought, the National Centers for Environmental Prediction's (NCEP) seasonal numerical weather prediction (NWP) model failed to detect the looming precipitation anomaly. The 2015 annual assessment of the Climate Forecast System, version 2 (CFSv2), found that it actually predicted slight positive precipitation anomalies for the March-May 2015 period when the historic drought initiated (Wang 2016) as well as the entirety of the ERS in Puerto Rico (Fig. 1). Fortunately, recent analyses of Puerto Rican hydroclimate have been aided by a newly developed convective potential index development specifically for the tropics, the Gálvez-Davison index (GDI). Daily values of this unitless composite parameter were shown to correlate with post-Hurricane Maria cloud cover over Puerto Rico (Miller et al. 2019b), whereas ERS mean GDI was shown to correspond strongly with coincident precipitation totals across the island (Miller et al. 2019a). Similarly, Ramseyer et al. (2019) found that daily GDI, when incorporated into a neural network, could help predict ERS dry day occurrence with $>90 \%$ accuracy in eastern Puerto Rico. Given the recent developments supporting the GDI's utility in precipitation analyses, a natural extension of the aforementioned work 
is to ask, "Could NWP models have successfully forecasted the anomalously low GDI associated with the 2015 Caribbean drought?"

The Weather Prediction Center (WPC) currently produces publicly accessible GDI forecast maps from the fourtimes-daily operational Global Forecast System (GFS) initializations. However, the GFS only extends 14 days beyond the initialization time, and consequently, cannot provide the lead time necessary to produce a seasonal GDI forecast. In contrast, the CFSv2 (hereafter simply CFS), operated by NCEP, provides $\sim 9$-month global forecasts following its operationalization in 2011. Though coarser than the GFS, this study will assess the ability of the CFS to anticipate seasonal drought events in Puerto Rico such as the 2015 drought.

\section{Data and methods}

The GDI will be derived from CFS ERS forecasts from 1 January through 31 March for 2012-18. The evolution of the forecast ERS GDI will then be analyzed to determine if (and potentially with what lead time) the CFS can yield reliable predictions of Puerto Rico GDI values. Additionally, the CFS GDI forecasts will be used to predict coincident precipitation totals using the statistical relationships developed by Miller et al. (2019a). This study will evaluate an accessible, reproducible framework for anticipating drought with months-long lead time in a hydrologically vulnerable region that is highly relevant to emergency and water managers in Puerto Rico and elsewhere in the Caribbean.

Operationalized by NCEP in March 2011, the CFSv2 (Saha et al. 2014) is a fully coupled land-ocean-atmosphere model with T126 spectral resolution, corresponding to roughly $100-\mathrm{km}$ gridded resolution, and 64 hybrid sigmapressure vertical levels. The CFS, which shares many similarities with the Climate Forecast System Reanalysis (CFSR), is initialized four times daily, producing $\sim 9$-month forecast period with output available every $6 \mathrm{~h}$. For this study, 0000 UTC CFS forecasts from the National Centers for Environmental Information (NCEI) were gathered for every other day beginning on 1 January of each year, the first CFS forecast capturing the entire ERS. For each initialization, the forecast conditions were retrieved for only 0000 UTC each day during the 122-day ERS. The 0000 UTC output fields along were selected to minimize the data retrieval burden required for the analysis, while also capturing the thermodynamic state of the atmosphere nearest to the evening TJSJ radiosonde launches described later in this section.

Prior to the operationalization of the CFSv2, NCEP produced limited reforecasts covering the period from 1982 to 2011. Extended-range reforecasts are available at 5-day, rather than daily, intervals, as is the case for the operational CFSv2. Further, only reforecasts initialized during February and March encompass the entire ERS. Because of the limited reforecast availability (6 forecasts during the 30 days preceding the ERS versus 15-16 forecasts via the data retrieval described above), reforecasts will not be used to generate seasonal GDI forecasts as with the operational runs, but rather will help interpret any drought signal present in the 2015 forecast by comparison to a larger sample of comparable simulations.

The CFS has a rich legacy of providing seasonal and subseasonal precipitation forecasts as intended. For instance, Tian et al. (2017) assessed CFS precipitation and temperature forecast skill over the conterminous United States, while Kim et al. (2012) focused on the entire Northern Hemisphere. Although space, time, and environmental factors are significant, their work suggests robust application for precipitation forecasts. However, within a multimodel global drought forecasting investigation, the CFS failed to represent some small-scale forcings (Yuan and Wood 2013). CFS forecasts have also been used to predict more acute hazardous weather phenomena such as hail and tornado activity (Carbin et al. 2016; Lepore et al. 2018).

At each CFS forecast period (i.e., daily 0000 UTC fields during the ERS), the authors computed the GDI for the entire tropical North Atlantic. The GDI was developed by Gálvez and Davison (2016) as a method of characterizing convective potential specifically in tropical environments. The GDI is the sum of three component terms, the column buoyancy index (CBI), the inversion index (II), and the midlevel warming index (MWI). The CBI is a positive term corresponding to the concentration of heat and humidity in the vertical, whereas the II is a negative term representing the detrimental effects of the trade wind inversion. The MWI is a simple modification of the $500-\mathrm{hPa}$ temperature reflecting the stabilizing/destabilizing effects of warm ridges/cool troughs. For each CFS initialization, the mean GDI is calculated for each month, April-July, as well as the entire ERS. The mean ERS GDI was computed by averaging all 0000 UTC GDI forecasts during the 122-day ERS for each semidaily CFS initialization. Thus, each year received $\sim 45$ ERS GDI forecasts (one forecast every two days for 90 days), except for 2016 (46 forecasts due to leap year) and 2017 (35 forecasts due to corrupted archive files prior to 19 January).

The CFS GDI forecast is assessed across four different scales, the tropical North Atlantic (TNA), eastern Caribbean, Puerto Rico, and San Juan, PR (Fig. 1). For the first three domains, ERA5 reanalysis (European 
Initialization Month: 01

April

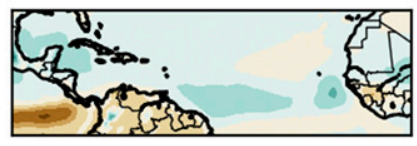

May

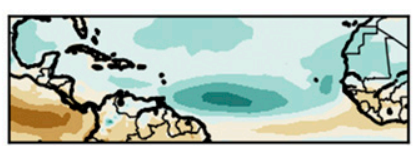

June

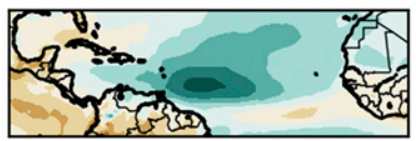

July

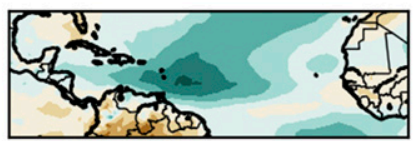

ERS

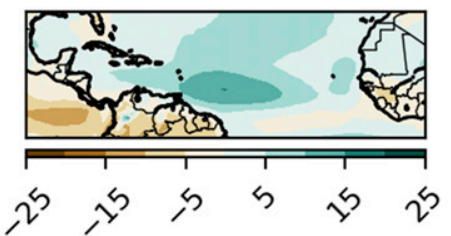

Initialization Month: 02
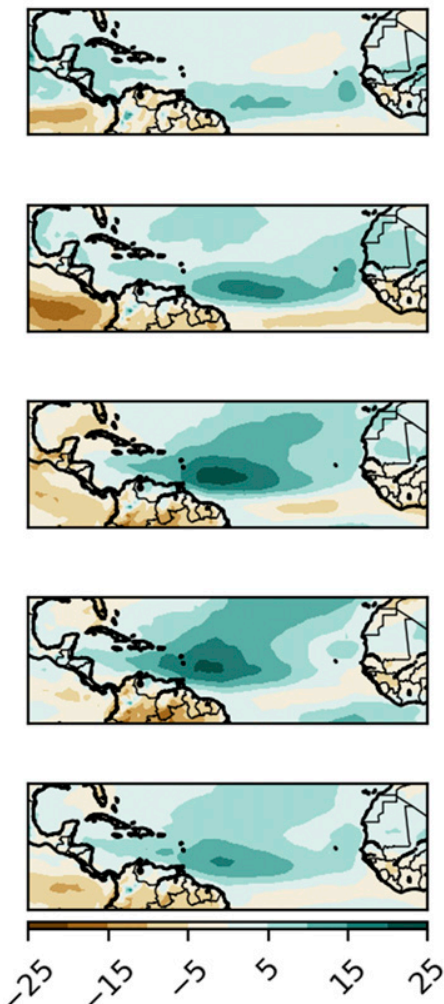

Initialization Month: 03
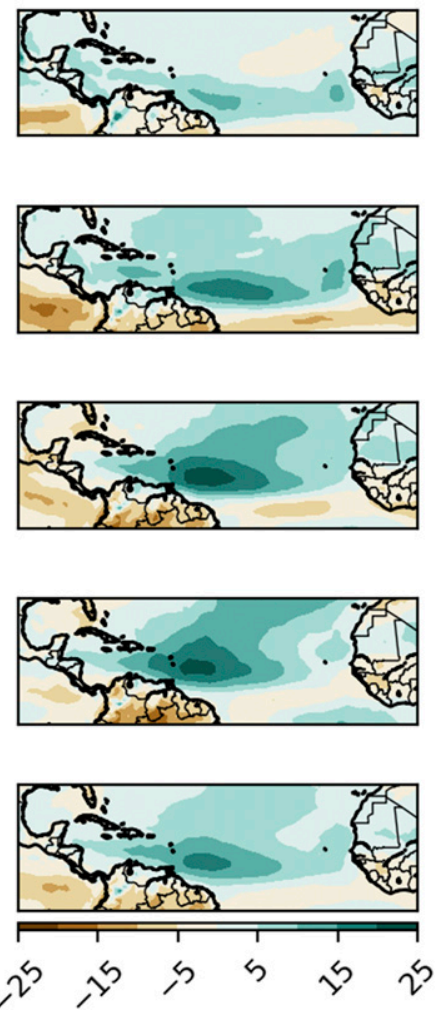

CFS GDI Bias 2012-2018

FIG. 2. CFS GDI bias calculated by subtracting the 7-yr ERA5 mean GDI from the CFS GDI. Bias maps are stratified by initialization month and forecast period.

Centre for Medium-Range Weather Forecasts 2017) serves as the verification field. ERA5 is produced using 4D-Var data assimilation in CY41R2 of ECMWF's Integrated Forecast System, and it is the highest resolution global reanalysis product available with 137 vertical model levels and a spatial resolution of $\sim 31 \mathrm{~km}$. The $1^{\circ} \times 1^{\circ}$ ERA5 grid is used to match the spatial resolution of the CFS. As with the CFS output, the GDI is calculated for each 0000 UTC period between April and July, and then averaged by month as well as the entire ERS. For the finest scale, the sole CFS grid cell containing San Juan, PR, is extracted, and compared against observed GDI derived from 0000 UTC San Juan, PR, radiosonde launches (TJSJ). These sounding data were retrieved from the IGRA, version 2, dataset (Durre et al. 2006). The CFS's ability to detect the 2015 Caribbean drought is assessed by comparing the mean 2015 GDI to nondrought years as the initialization time approaches the start of the ERS. Further, the 2015 GDI will be contextualized within the larger CFS reforecast and ERA5 periods of record to determine if the GDI was forecasted to occupy an appreciably low percentile.
The evolution of the forecast GDI is tracked for each of the four domains.

Uniquely for the San Juan domain, the forecast GDI can serve as the basis for a seasonal QPF prediction. Miller et al. (2019a) developed an empirical relationship between the mean ERS GDI determined from 0000 UTC TJSJ radiosonde observations and the total ERS precipitation in Puerto Rico. After comparing and calibrating the mean CFS-predicted ERS GDI to TJSJ radiosonde-derived values, the calibrated CFS is used to predict island-averaged precipitation from the linear regression relationship developed by Miller et al. (2019a). In the aforementioned analysis, mean GDI values corresponded strongly to ERS precipitation with $R^{2}=0.82$ though correlations were much weaker outside of the ERS. Equation (1) describes the ERS GDI-precipitation relationship (Miller et al. 2019a):

precipitation $(\mathrm{mm})=275.6 \mathrm{~mm}+\left(47.91 \frac{\mathrm{mm}}{\mathrm{GDI}}\right) \times \mathrm{GDI}$ 


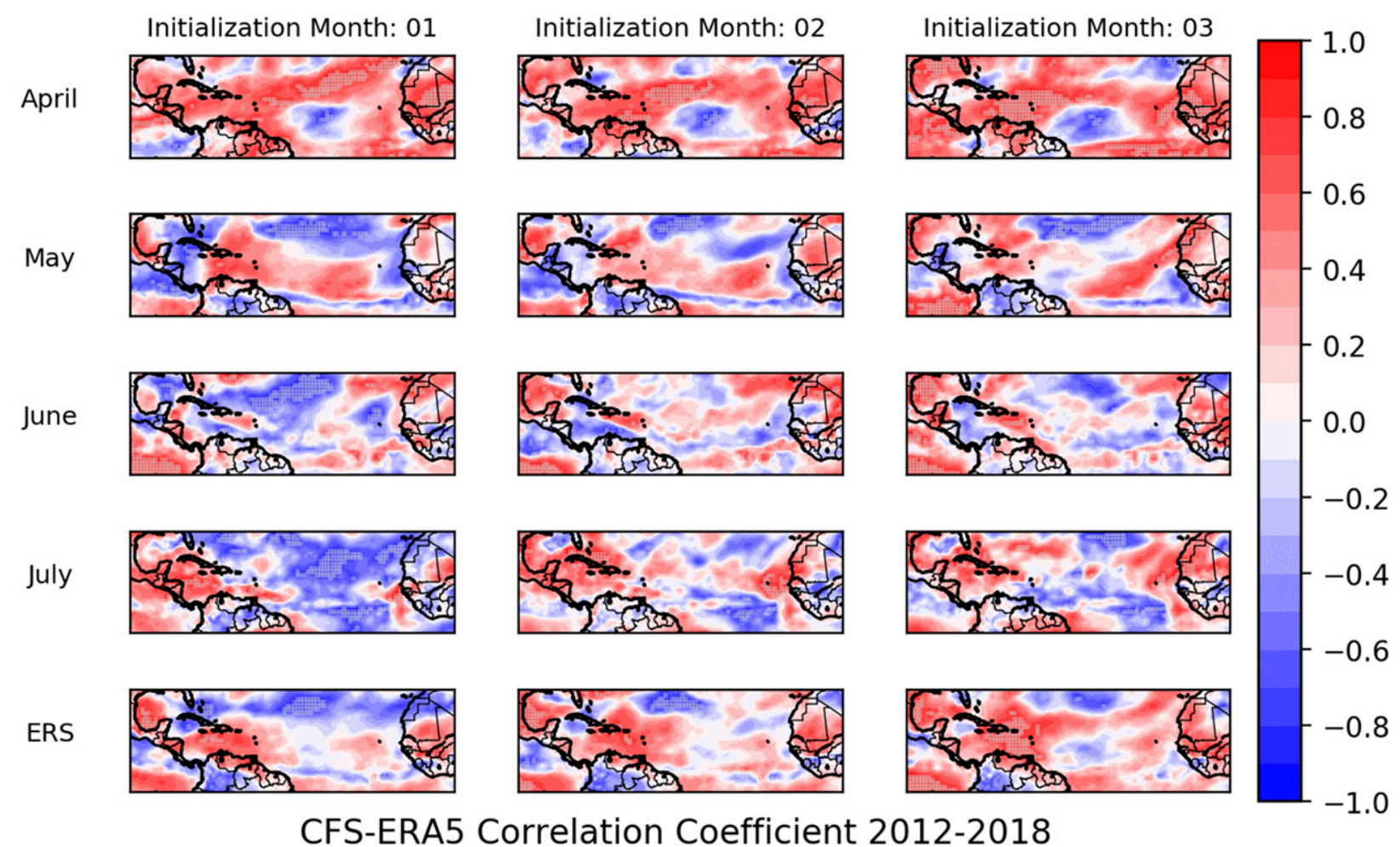

FIG. 3. Pearson correlation coefficient $(R)$ values for the 7-yr CFS-ERA5 relationship. The $R$ maps are stratified by initialization month and forecast period, and statistically significant cells with a $p$ value $<0.05$ are stippled.

Climatological observed precipitation is determined from the Daymet precipitation archive (Thornton et al. 2017), a 1-km gridded daily precipitation estimate previously utilized in Puerto Rico hydroclimate analyses (Mote et al. 2017).

\section{Results}

Results will be presented for each of the domains shown in Fig. 1. CFS GDI forecasts were binned by initialization month (i.e., January, February, and March), representing a 60-90-, 30-60-, and 0-30-day lead time, respectively.

\section{a. Operational CFS GDI validation}

CFS GDI forecasts for each lead time category (corresponding to the month the CFS was initialized) were compared to the ERA5 GDI valid for the forecast period (Figs. 2 and 3). Figure 2 depicts the CFS GDI bias across the entire TNA by subtracting the mean ERA5 GDI for all 7 years from the mean CFS GDI. Two areas of bias are clearly visible: a low bias over the eastern Pacific (CFS $<$ ERA5) and a high bias (CFS $>$ ERA5) east of the Lesser Antilles. The latter bias, which peaks in June and July at 20-25 units, is most relevant for the Puerto Rico drought forecast. Curiously, the high bias intensifies as the initialization period nears the forecast period. For instance, the ERS GDI forecast bias over Puerto Rico for all runs initialized in January is 3.11, whereas the bias increases to 4.86 and 5.61 for February and March initializations, respectively. Across all initializations, the high bias east of the Lesser Antilles is greatest during June and July when the maximum bias is roughly 23 and 21 units, respectively.

Although the CFS high-GDI bias increases as the lead time decreases, more importantly, the CFS becomes a more accurate predictor of GDI as the forecast period approaches. As the absolute values of GDI become more inflated, the covariability of the CFS and ERA GDI strengthens. Figure 3 depicts the Pearson correlation coefficient $(R)$ values between the CFS and ERA5 GDI with stippling marking grid cells with $p$ values $<0.05$. Although large areas of the CFS domain correspond weakly and/or inversely to the ERA5 GDI, $R$ values over the eastern Caribbean are some of the largest in the entire TNA, especially for March initializations. Even during the January initializations, the earliest CFS runs that capture the entire ERS, pockets of 


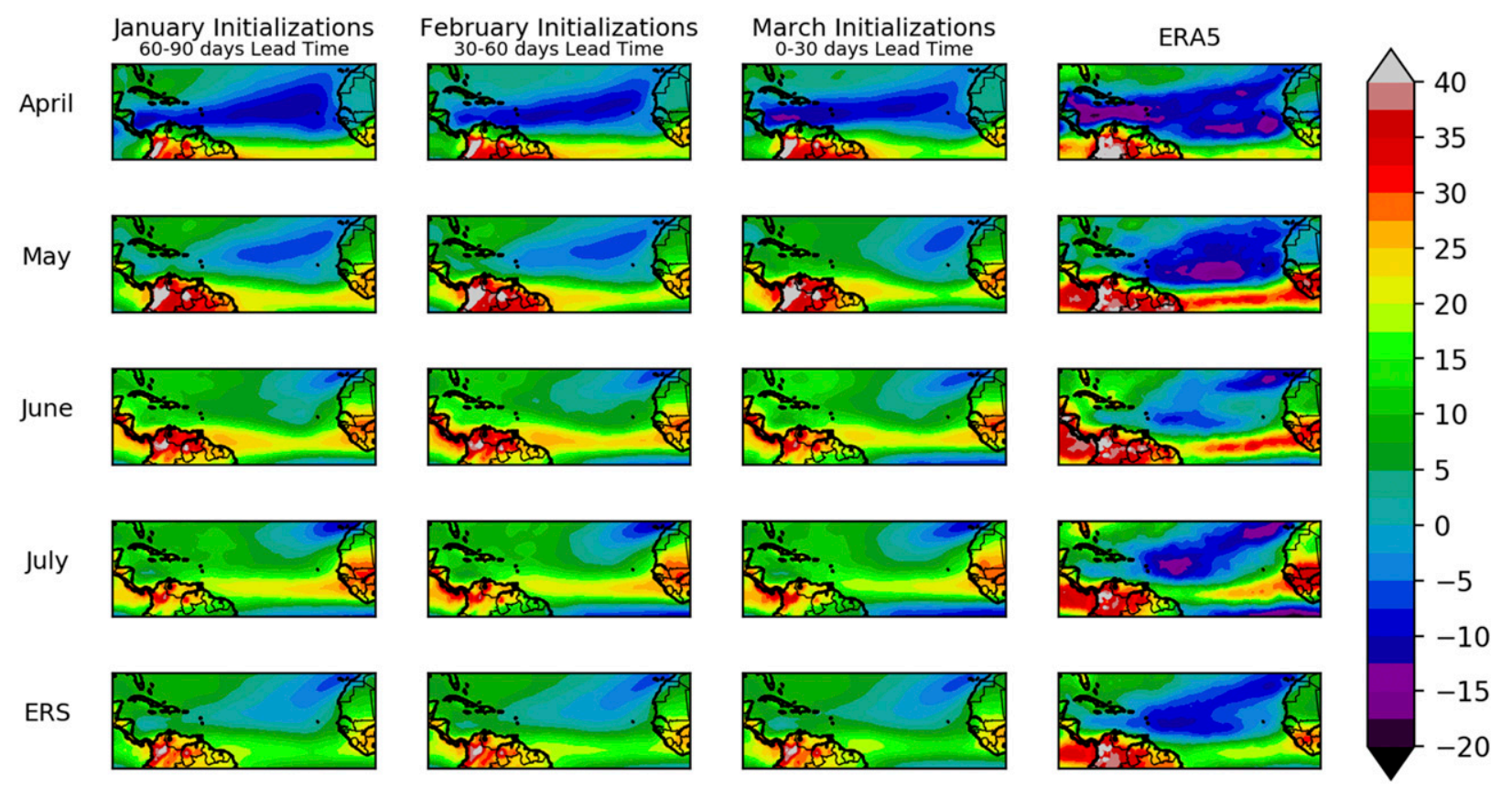

CFS GDI Forecasts: 2015

FIG. 4. CFS GDI forecasts for the entire TNA during the 2015 ERS. Forecasts are averaged for January, February, and March initializations and with the ERA5 reanalysis pictured for validation.

statistical significance are present in the Caribbean. Specifically, over the island of Puerto Rico, the mean $p$ value for the CFS-ERA5 ERS relationship strengthens from 0.27 for January initializations to 0.10 and 0.02 for February and March initializations, respectfully. Thus, CFS forecasts begin detecting a meaningful ERS GDI signal at least one month before the onset of the ERS.

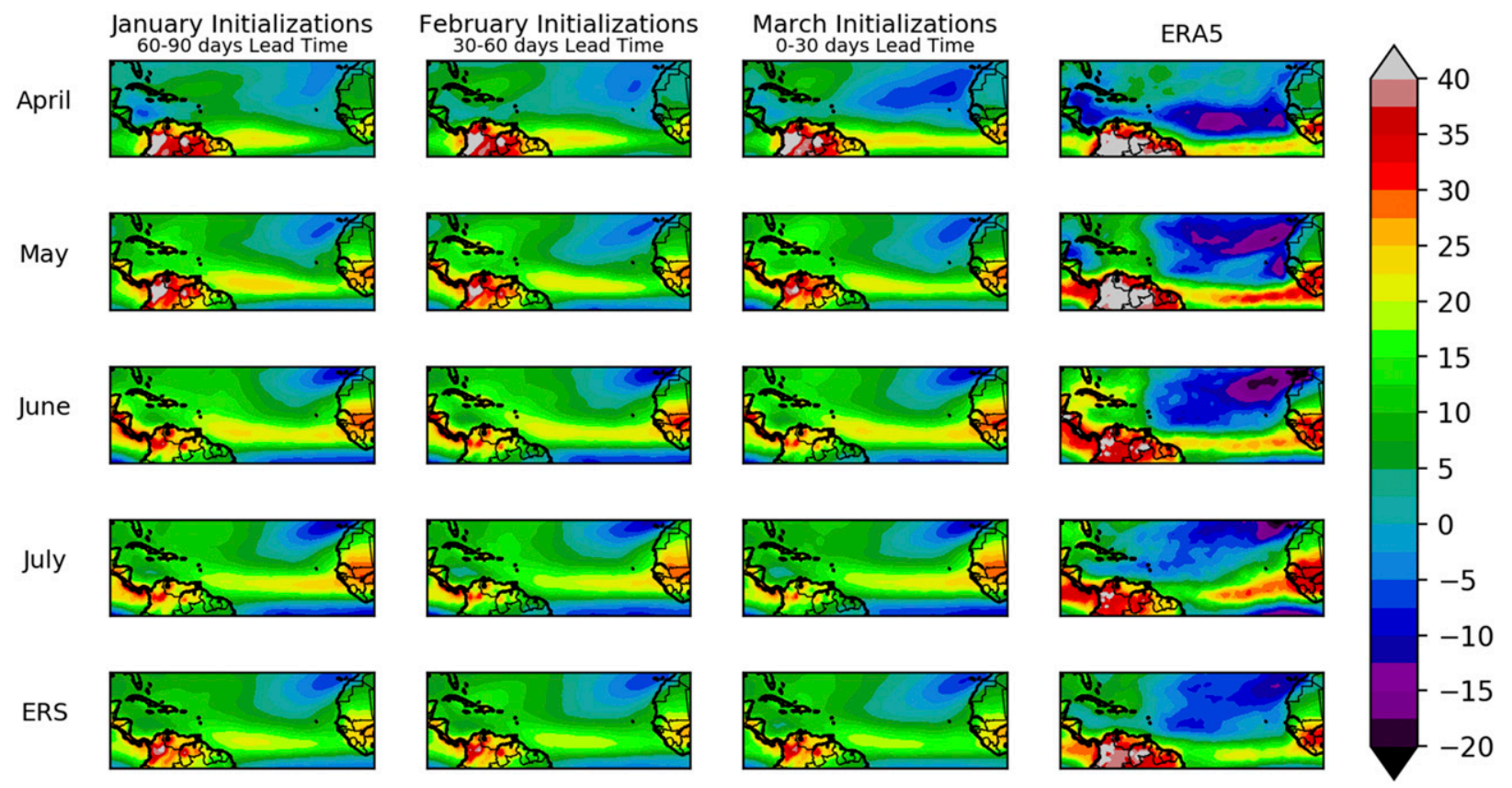

CFS GDI Forecasts: 2016

FIG. 5. As in Fig. 4, but for 2016. 


\section{b. Drought detection during CFSv2 operational lifetime}

To highlight a potential drought signal in CFS forecasts, the predicted GDI for 2015, which witnessed the prolific Caribbean drought, is compared to 2016, a slightly wetter-than-average ERS. Mote et al. (2017) thoroughly documented the evolution of the 2015 Puerto Rico drought in relation to the SAL, which was characterized by exceptionally low GDI values indicating the reduced potential for convective precipitation. Thus, comparatively low GDI values during 2015 will serve as evidence that the CFS is resolving this important drought-causing mechanism. Figure 4 shows the ERS CFS forecast for 2015 which clearly depicts a tongue of depressed GDI values extending from the Sahara to the eastern Caribbean. This feature was forecast to be most prominent in April, which corresponds well to its maximum intensity in the ERA5 dataset. However, the CFS forecasts steadily increase the GDI values within the SAL as the lead times decreases such that the March initializations forecast a less intense SAL than the earliest CFS runs. When compared to 2016 (Fig. 5), a wetter-than-average ERS, the 2015 SAL signature in the CFS forecast becomes even more apparent. In 2016, January CFS initializations do not even contain a -10 GDI contour for April, and GDI predictions for the entire eastern Caribbean are roughly 5-10 units greater than predicted for 2015. Though Figs. 4 and 5 are only case studies of the CFS performance in the ERS, this example illustrates the ability of the CFS to distinguish between an exceptionally drierthan-average ERS and a wetter-than-average ERS with several months lead time.

Despite the somewhat weak correlation coefficients for January and February initializations (Fig. 3), the CFS GDI forecast still provides value by detecting the driest years with several months lead time. The correlation coefficient is sensitive to instances where the CFS forecast misdiagnoses relatively average GDI years as above-average years; however, advance notice is most crucial only for the lowest GDI, and consequently, drought-prone years. Therefore, Fig. 6 displays the 7-yr time series of the CFS GDI forecast as well as the ERA5 GDI for the eastern Caribbean, Puerto Rico, and San Juan domains. For the San Juan, PR, domain, the GDI computed from the TJSJ radiosonde serves as the validation dataset. According to the time series in Fig. 6, the CFS clearly captures the broadest patterns of the eastern Caribbean GDI time series as early as January. The CFS initializations during this timeframe were less accurate as the spatial domain narrows to PR only and San Juan only. The CFS also stumbles in 2013, by missing the relatively large GDI values that year, as well as 2018 when it only projected a marginal decrease in GDI from 2017.

However, in the broadest sense, the CFS captures some of the most prominent and important features of the time series. For instance, the CFS replicates the sharp transition of low GDI values during the 2015 ERS to high values in 2016. Further, and perhaps, most importantly, the March CFS initializations identify the three lowest GDI years over all three domains in Fig. 6 (i.e., 2014, 2015, 2018). In fact, within the Puerto Rico domain, the CFS identifies these same three years a month earlier, during its February initializations. As the GDI-precipitation findings of Miller et al. (2019a) suggest and Fig. 6 also shows, these three lowest GDI ERSs were also the three driest years across Puerto Rico. As rule of thumb during the 7 years analyzed, whenever the mean ERS GDI predicted by March CFS initialization was less than 7.5, Puerto Rico experienced below-average ERS precipitation.

\section{c. $Q P F$ validation}

Whereas section $3 b$ identified episodes of low forecast GDI values to hindcast drought, this section will leverage the empirical GDI-precipitation relationship [Eq. (1)] developed by Miller et al. (2019a) to produce a CFS QPF tool for Puerto Rico. Because Eq. (1) was computed using GDI values derived from the TJSJ radiosonde deployments, the CFS output for the cell containing San Juan, PR (Fig. 1), will be calibrated against observed TJSJ GDIs for the same period. Overall, the CFS forecast for San Juan, PR, yields ERS mean GDIs that are roughly 1.5 units too high compared to TJSJ radiosondes. The measured mean ERS GDI between 2012 and 2018 was 4.82 (Table 1) versus 6.25 predicted by the CFS. However, consistent with the TNA forecasts in Fig. 2, CFS GDI forecasts initialized during January, 3 months before the onset of the ERS showed a smaller high bias than those produced in March, the month immediately prior to the ERS.

As the CFS initializations approach the onset of the ERS, the relationship between predicted and observed GDI strengthens (Fig. 7). The observed-predicted $R^{2}$ values steadily increase from 0.13 to 0.27 to 0.55 for initializations during January, February, and March, respectively. Though the CFS-predicted GDI explains $55 \%$ of the variability in actual ERS GDI during the month immediately preceding the ERS, the $0.056 p$ value for this relationship lies just beyond the 0.05 significance level. The near significance is likely related to the small, 7-yr dataset used to form the relationship. In fact, when the correlation is recalculated with integer-only precision, the $p$ value for March initializations decreases to 0.031 .

Using the linear regression relationships plotted in Fig. 7, the San Juan-only CFS mean GDI prediction is calibrated to yield GDI values that more closely correspond 


\section{January Initializations}

60-90 days Lead Time
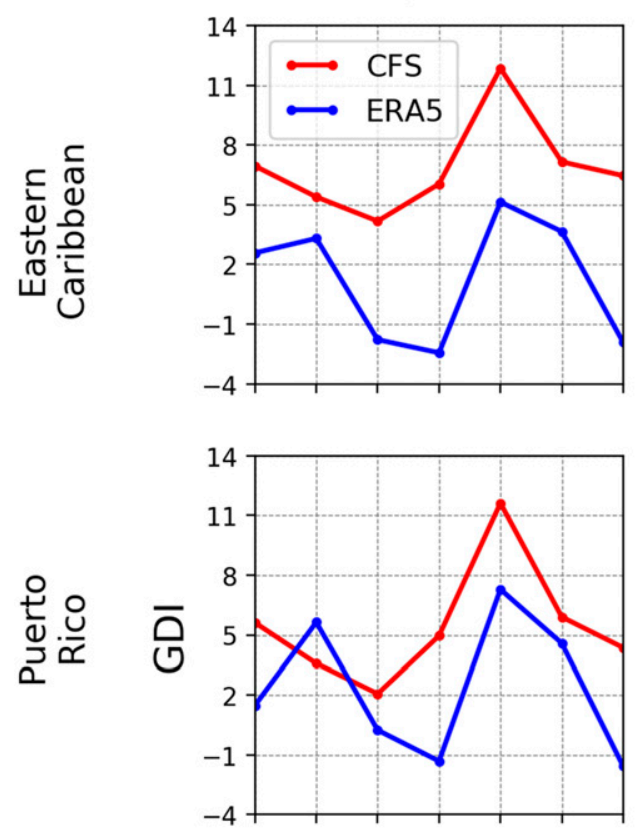

ํํㄹำ
February Initializations 30-60 days Lead Time
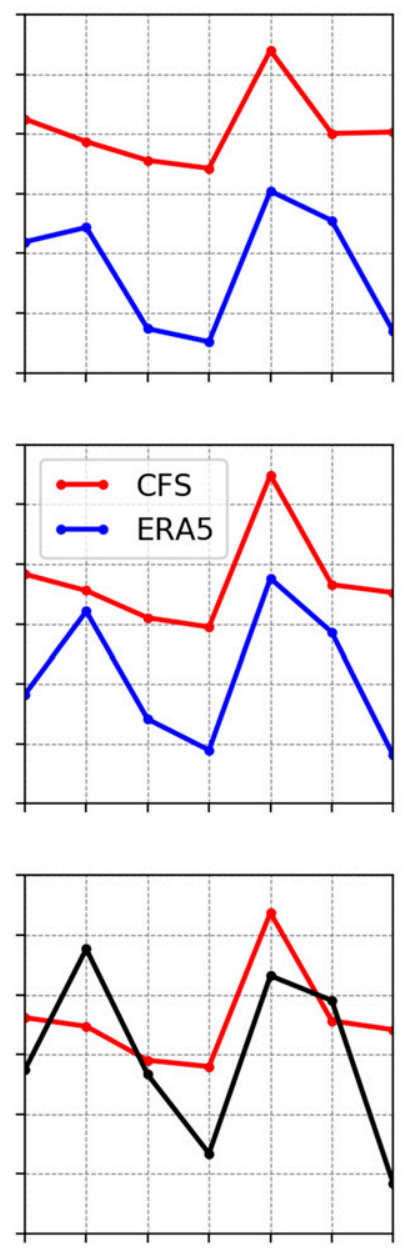

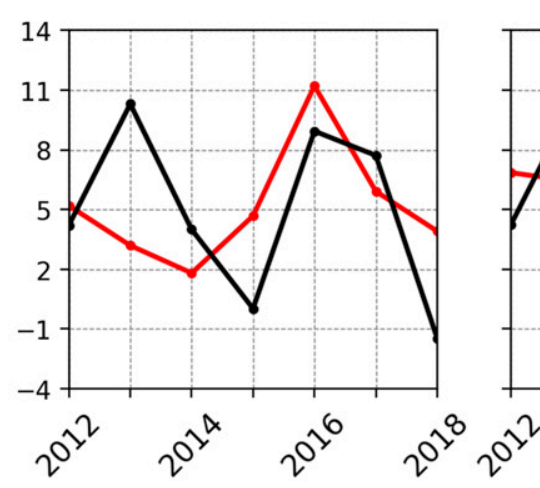

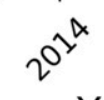

Year
March Initializations

0-30 days Lead Time
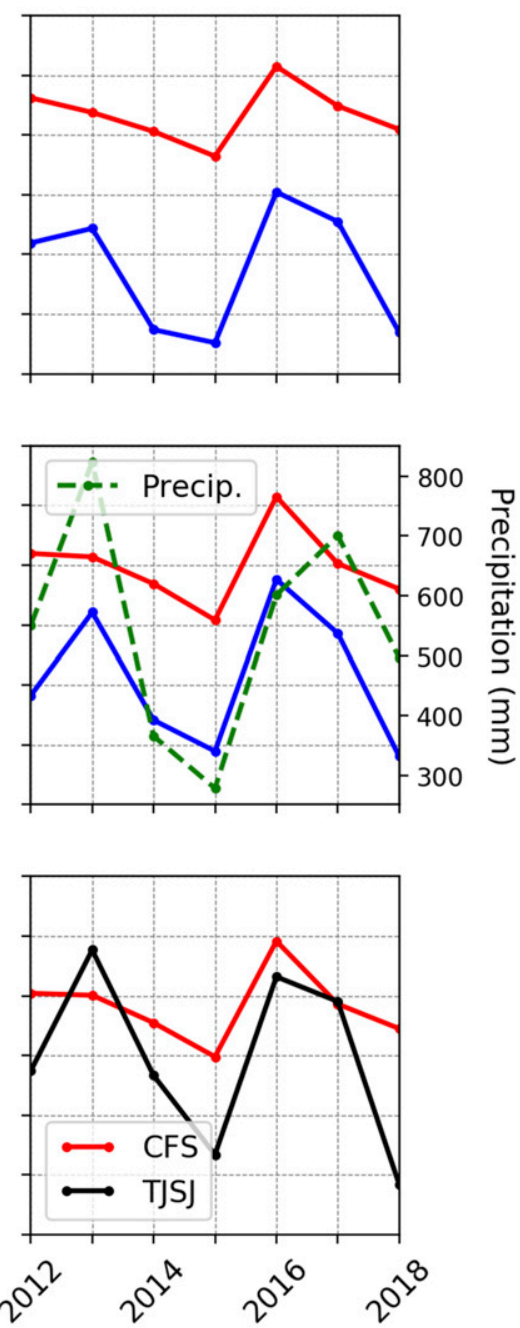

FIG. 6. Time series of CFS vs ERA5/TJSJ-derived GDI for each of the three domains shown in Fig. 1. The observed precipitation for the Puerto Rico domain is based on the ERS island-wide average precipitation from the Daymet dataset.

to the observed GDI means. This calibration will allow the CFS-predicted means to be inserted into the seasonal QPF tool displayed in Eq. (1). Because the CFS GDI bias grows larger as the ERS approaches nearer (Table 1), a different calibration is developed for the January, February, and March initializations [Eqs. (2)-(4)], respectively:

$$
\begin{aligned}
& \mathrm{GDI}_{\text {Calib }}=2.12+0.52 \times \mathrm{GDI}, \\
& \mathrm{GDI}_{\text {Calib }}=-1.36+0.91 \times \mathrm{GDI}, \\
& \mathrm{GDI}_{\text {Calib }}=-8.73+1.81 \times \mathrm{GDI} .
\end{aligned}
$$

After tuning the forecast ERS GDI using Eqs. (2)-(4), the calibrated value is then inserted into Eq. (1) to produce the ERS QPF. Because the QPF is a simple linear transformation of the GDI, its time series is not shown. Instead, the CFS QPFs are compared against the climatology forecast to demonstrate the added value of the GDI-based QPF.

Because the focus of this paper is advanced detection of the driest years (specifically, 2015), Fig. 8 illustrates the percent error of the CFS and climatology QPF as a function of the ERS total precipitation. The mean island-wide ERS precipitation between 1981 and 2010 was $510 \mathrm{~mm}$ for Puerto Rico. This climatological forecast was, by definition, most accurate for near-normal ERSs while poorest for exceptionally dry or wet ERS years. Compared to the climatology forecast, the GDI-based 
TABLE 1. Mean ERS GDI values calculated from TJSJ radiosondes and the CFS grid cell containing San Juan, PR (Fig. 1b). CFS means are aggregated across the entire ERS study period and also stratified by initialization month. (C.I. stands for confidence interval.)

\begin{tabular}{lc}
\hline \multicolumn{1}{c}{ Source } & Mean ERS GDI (95\% C.I.) \\
\hline TJSJ & 4.82 \\
Jan-Mar CFS & $6.25(5.86-6.64)$ \\
Jan CFS & $4.77(4.04-5.50)$ \\
Feb CFS & $6.71(6.07-7.36)$ \\
Mar CFS & $7.26(6.69-7.83)$ \\
\hline
\end{tabular}

QPF shows that it is more skillful, particularly for the driest years. For January CFS initializations, the precipitation-percent error regression functions are fairly similar with the CFS QPF characterized by a smaller percent error during the driest years. The difference between the CFS and climatology "forecasts" becomes more apparent among the February and March initializations. With each successive month, the CFS 95\% confidence interval for the percent error includes $0 \%$ over a greater range of ERS precipitation totals. In particular, by February, the $95 \%$ confidence intervals between the CFS QPF and the climatology forecasts contain only minimal overlap, with the confidence intervals for dry years completed separated during the March initializations. Thus, the CFS-based QPF is a statistically significant improvement over climatology for the driest years in the CFS operational lifetime. In contrast, the mean ERS QPF predicted by the CFS for Puerto Rico during March initializations was $533 \mathrm{~mm}$ (Fig. 1a), compared to $285 \mathrm{~mm}$ produced by the GDIbased method. The former represents a $+4.7 \%$ precipitation anomaly, whereas the observed 2015 ERS precipitation, $279 \mathrm{~mm}$, was a $-45.3 \%$ departure from normal (Fig. 1a).

\section{d. Contextualizing the 2015 CFS forecast}

Though the CFS performance during its operational period is promising, the brief 7 -yr sample size prevents more confident conclusions about its drought detection skill. To form stronger determinations, two additional methods are implemented to contextualize the potentially anomalous nature of the 2015 GDI forecast. The first method mirrors the calibration used to fit the CFSpredicted GDI values for San Juan to the TJSJ-observed GDI during the same period. However, this case, the CFS mean ERS GDIs for the eastern Caribbean and Puerto Rico will be calibrated against the same spatial averages from the ERA5 reanalysis. Figure 9 depicts the regression relationships for each lead time category and region. The fitted regression shown in Fig. 9 can be used to generate a calibrated CFS GDI forecast that can be compared to the 40-yr ERA5 period of record.

Table 2 provides the calibrated ERS GDI forecasts as well as the percentile rank of these values within the ERA5 distribution. The percentile rank of the eastern Caribbean GDI steadily decreases as the lead time decreases and approaches the forecast period. However, the calibration, (performed separately for each lead time category based on the regression equations shown in Fig. 9), is not statistically significant until the 0-30-day lead time category. During this period, the calibrated GDI predicted by the CFS fell within 16.3th percentile of the 40-yr ERA5 GDI distribution. Similarly, neither does the forecasted Puerto Rico GDI statistically significantly correspond to the ERA5 mean until the 0-30-day lead time category. Within 30 days of the ERS

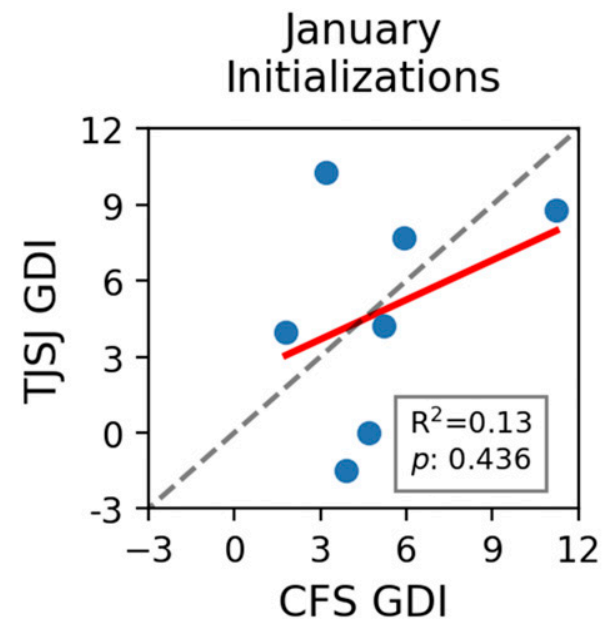

\section{February Initializations}

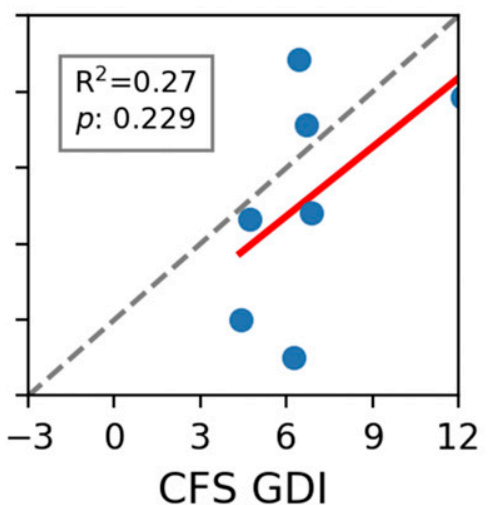

March Initializations

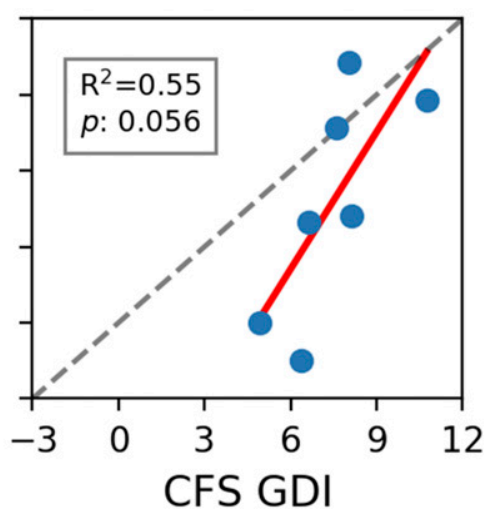

FIG. 7. Mean ERS GDI predicted by the CFS during all initializations collected in each month is plotted against the observed GDI from TJSJ radiosondes for the same forecast period. The least squares regression relationship (red line) is also plotted for each month. 

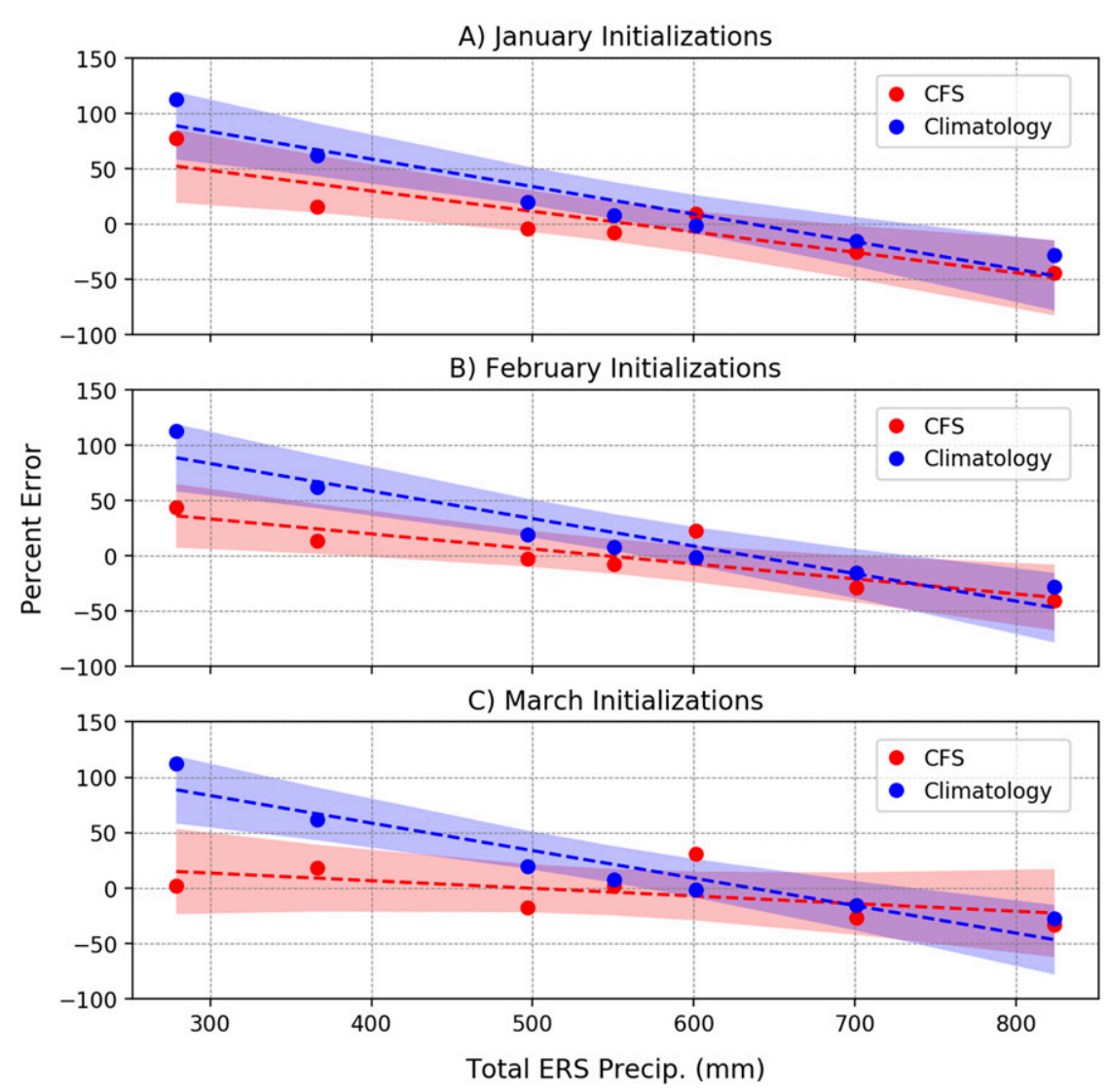

FIG. 8. Percent error for CFS total ERS precipitation forecast (red) for (a) January, (b) February, and (c) March initializations vs climatology (blue). The percent error is proportional to the difference between the statistical Puerto Rico QPF forecast determined using Eq. (1) and the island-averaged total ERS precipitation from the Daymet dataset. The dashed lines depict the ordinary least squares regression relating the percent error to the total ERS precipitation, and the shaded regions correspond to the $95 \%$ confidence intervals for the likecolored regressions.

onset, the calibrated 2015 CFS GDI occupied the 13.8th percentile of the 40-yr ERA5 distribution.

The second method leverages the longer period of record available for CFSv2 reforecasts produced by NCEP. As mentioned in section 2, the reforecasts, though extending further into the historical record, are initialized at a coarser temporal resolution than their operational counterparts. However, characterizing the CFS-predicted 2015 GDI within the 37-yr reforecast record provides a more direct, apples-to-apples-type comparison than the ERA5-based method. Because the CFS demonstrated a persistent high bias, any effort to compare the 2015 CFS GDI to the ERA5 dataset necessarily involves a calibration technique like the one performed in Fig. 9. Instead, computing the percentile rank of the 2015 CFS GDI within the 37-yr reforecast/operational dataset neutralizes the CFS's high bias by allowing it to equally affect all forecasts in the distribution. Over the eastern Caribbean, the 2015
GDI predicted by the CFS with a 0-30-day lead time resided in the 23.0th percentile of all 1982-2018 ERS forecasts (Table 3). In contrast, when the GDI was spatially averaged over Puerto Rico alone, the 2015 CFS forecast represented the 14.9th percentile (Fig. 10). Though not shown in Table 3, the forecasted April-only GDIs over both the eastern Caribbean and Puerto Rico were the lowest in the entire CFS reforecast/operational period of record.

\section{Discussion}

Drought in the eastern Caribbean has important ecological and economic impacts, and seasonal-scale predictability can provide months-long lead time to prepare stakeholders for dry conditions. The results presented here indicate that using the CFS-based GDI forecasts can provide a skillful tool in predicting drierthan-normal ERSs. In particular, the CFS showed 
Eastern Caribbean

60-90 Day

Lead Time

30-60 Day

Lead Time

0-30 Day

Lead Time
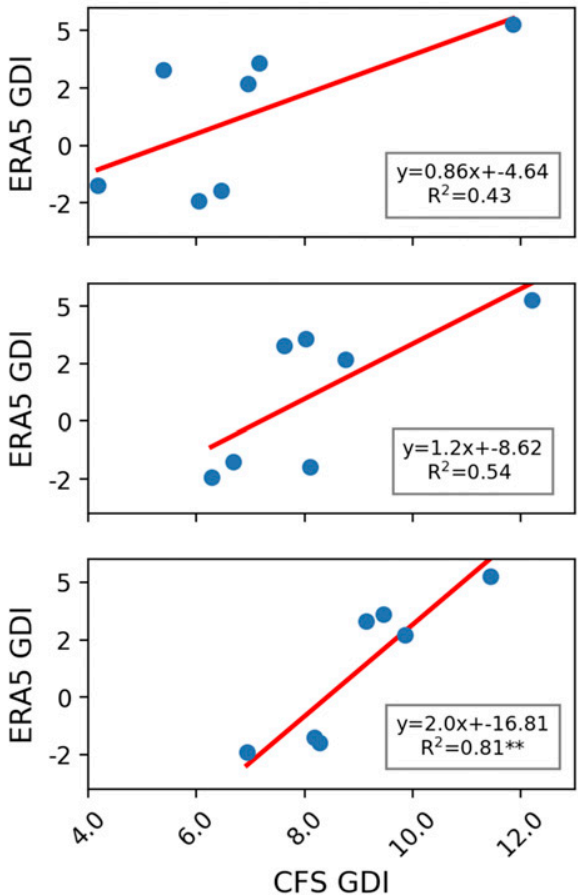

Puerto Rico
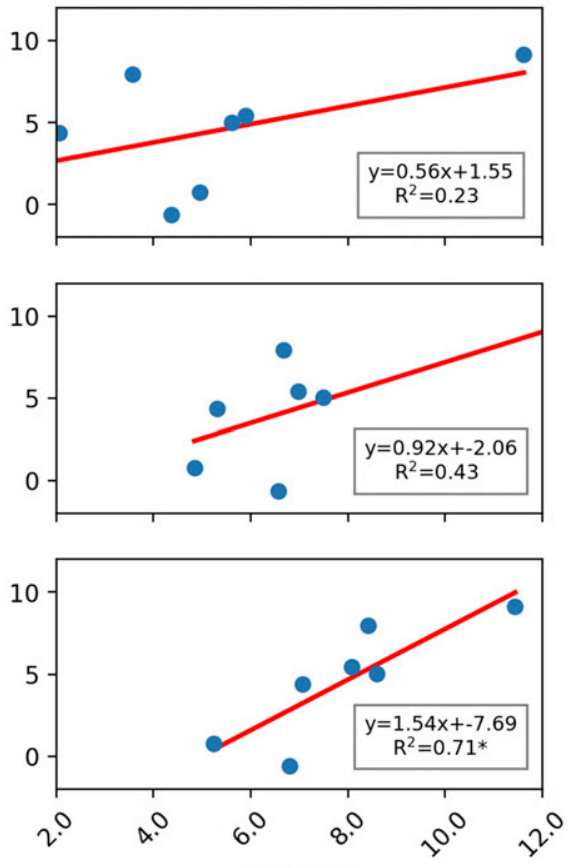

CFS GDI

FIG. 9. Calibration functions used to adjust the CFS-predicted GDI for the ERS to representative ERA5 values. The best-fit regression equations represented by the red lines are shown in the bottom right corner of each pane along with their associated coefficient of determinations $\left(R^{2}\right)$. Coefficient of determinations with $p$ values $<0.05$ and $<0.01$ are denoted by $*$ and $* *$, respectively.

statistically significant skill in identifying the driest year (2015) across the eastern Caribbean with a 1-month lead time (Fig. 8). Additionally, the CFS uniformly forecasts the transition from the driest to the wettest ERS (2015-16) across each scale analyzed.

When contextualized within a climatological period of record using two different methods, the 2015 CFS ERS forecast represented approximately the lowest $15 \%$ of all CFS GDI forecasts over the island of Puerto Rico under both techniques. Though the CFS did not predict 2015 as the lowest GDI on record, it did correctly place it in a climatologically low percentile with up to 30 days of lead time. The $\sim 15$ th percentile predicted by the CFS is comparable to existing hydrological drought criteria.
For instance, the National Drought Monitoring Center currently defines "moderate drought" as the 11-20th percentiles of streamflow and soil moisture (Svoboda et al. 2002). Moreover, the standardized precipitation index (SPI) (McKee et al. 1993), which is uniquely tied to probability, defines drought as SPI $\leq-1.00$. This SPI threshold is established so that locations spend approximately $16 \%$ of their time in this category, which again aligns with the $\sim 15$ th GDI percentile predicted by the CFS in 2015.

The CFS's proficiency at detecting GDI anomalies with appreciable lead times is especially important given the model's failure to detect reduced 2015 rainfall in its explicit precipitation fields as described in section 1.

TABLE 2. Percentile ranks of calibrated CFS GDI forecasts for the 2015 ERS using the regression relationships shown in Fig. 9. Eastern Caribbean and Puerto Rico percentiles are determined from the 40-yr (1979-2018) GDI climatology computed from ERA5 reanalysis.

\begin{tabular}{lccccc}
\hline \multicolumn{1}{c}{ Region } & Lead time (days) & CFS mean ERS GDI & Calibrated ERS GDI & $p$ value of calibration & Percentile rank \\
\hline Eastern Caribbean & $60-90$ & 6.04 & 0.55 & 0.11 & 36.3 \\
& $30-60$ & 6.28 & -1.10 & 0.06 & 27.5 \\
Puerto Rico & $0-30$ & 6.93 & -2.96 & 0.01 & 16.3 \\
& $60-90$ & 4.96 & 2.32 & 0.28 & 43.8 \\
& $30-60$ & 4.84 & 0.41 & 0.02 & 31.3 \\
\hline
\end{tabular}


TABLE 3. Percentile ranks of CFS GDI forecasts for the 2015 ERS within the 1982-2018 reforecast/operational period of record (CFS reforecasts for 1982-2011). Reforecasts, which were produced at less frequent intervals than operational forecasts, are only evaluated for the $0-30$-day lead time category.

\begin{tabular}{lcccc}
\hline \hline \multicolumn{1}{c}{ Region } & Lead time (days) & CFS mean ERS GDI & 37-yr mean ERS GDI & Percentile rank \\
\hline Eastern Caribbean & $0-30$ & 6.93 & 8.01 & 23.0 \\
Puerto Rico & $0-30$ & 5.24 & 7.03 & 14.9 \\
\hline
\end{tabular}

The 21-day CFS QPF (based on initializations during 1-10 February) for March, April, and May 2015, mostly aligning with the drought onset, predicted normal to slightly above normal precipitation across the eastern and central Caribbean (Wang 2016). The too-wet forecast was maintained during the entire ERS with the 16 March 2015 CFS initializations analyzed collectively predicting $+4.65 \%$ anomaly (Fig. 1c). Only one of the sixteen 0000 UTC CFS runs predicted a precipitation deficit comparable to what occurred. Thus, a CFS drought forecast cannot be obtained by simply consulting the modeled precipitation fields ahead of the upcoming ERS. The improvement of the GDIbased reforecasts upon the explicit CFS precipitation predictions illustrate the potential weakness of NWP convective and microphysics parameterizations when predicting seasonal totals, underscoring the value of the QPF technique demonstrated here.

In addition to the spatial representation of the SAL, the CFS-based GDI correctly captures the timing of the 2015 drought which initiated in Puerto Rico during April and reached peak intensity in early June (Mote et al. 2017). The CFS skillfully identifies the anomalously low GDI values over the eastern Caribbean domain at the April onset of the drought during each initialization window (Fig. 4, top row). Comparing the 2015 and 2016 ERS forecasts, the CFS detected a decidedly less favorable convective environment in 2015, particularly in April and May during the drought's initiation and intensification (Figs. 4 and 5). This finding implies that, although the CFS does not resolve dust emission or transport, it can resolve the synoptic- to global-scale atmospheric circulations that advect hot, dry air characteristic of the SAL.

The approach presented here is also a statistically significant advancement in drought prediction compared to climatology (Fig. 8). While the CFS forecasts and climatology both underestimate wet years and overestimate dry years (though this is a trivial statement for the climatology forecast), the CFS-based GDI technique convincingly outperforms climatology for the driest years. The CFS demonstrates a $\sim 50 \%$ error at $\sim 90$ days lead time for the most extreme dry year (Fig. 8a), which nonetheless represents a large improvement over climatology ( $89 \%$ error). From the
January to March initialization periods, the CFS shows steady improvement in drought predictability, likely due to the assimilation of more representative initial conditions. By the March initializations, the CFS is producing mean seasonal precipitation forecasts within $15 \%$ of the observed precipitation for 2015-type droughts (Fig. 8c). In contrast, the GDIbased QPF technique struggles during wet years. For January initializations, the mean CFS QPF underestimates precipitation by $48.6 \%$ for the most extreme wet years (Fig. 8a). Taken at face value, the CFS forecast is slightly more accurate than climatology for pluvial years, but only during February and March initializations. However, the $95 \%$ confidence intervals shown in Fig. 8 reveal that the GDI-based QPF is statistically indistinguishable from climatology in those environments.

Despite its encouraging performance, the CFS forecasts were also associated with apparent limitations, most notably the need to calibrate the CFS GDI due to a persistent high GDI bias across much of the TNA (Fig. 2). Figure 4 suggests that the overall positive GDI bias throughout the ERS in the Caribbean is largely produced during the June and July forecast period.

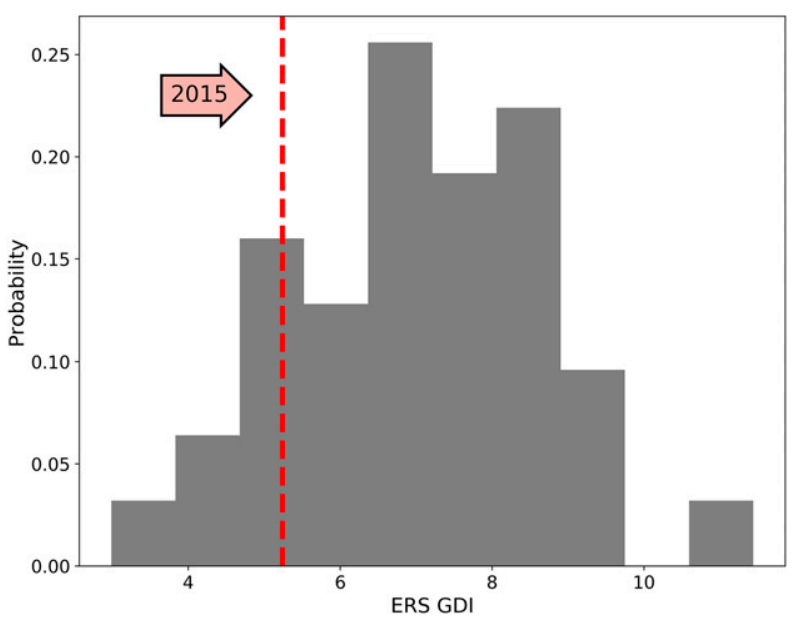

FIG. 10. Histogram of the CFS 37-yr (1982-2018) GDI distribution of all 0-30-day ERS forecasts averaged over all cells containing Puerto Rico. The position of the 2015 forecast within the distribution, corresponding to the 14.9 th percentile, is marked by the red dashed line. 
Upon initial inspection, such positive biases are likely partially driven by warm SST biases across this portion of the domain, particularly during the 2014 and 2015 drought years (Wang et al. 2015; Wang 2016); however, future research should more fully engage the high-GDI artifact. Additionally, the tongue of lower-than-normal GDI values observed during the 2015 drought across much of the TNA is not fully captured by the CFS (Fig. 4), which likely contributes to the high-GDI bias in the eastern Caribbean (Fig. 2). As described earlier, this feature is interpreted to indicate SAL outbreaks that occurred during the 2015 ERS (Mote et al. 2017). While the feature is not entirely resolved, the CFS does expand the lower GDI values farther west than climatology for the 2015 ERS, as seen by comparing Figs. 4 and 5. In 2015, the CFS predicted negative GDI values extending westward into portions of the eastern Caribbean (Fig. 4, bottom row), whereas in 2016, the negative GDI corridor only extends into the central tropical North Atlantic, several hundred kilometers east of Puerto Rico (Fig. 5, bottom row). Critically, this anomalous westward extent of lower GDI values in 2015 was predicted with a 3-month lead time; however, the CFS eventually dampened the low-GDI tongue as the forecast period drew nearer.

\section{Conclusions}

Drought early warning tools for Puerto Rico, as well as the broader eastern Caribbean, are sorely needed due to the extensive hydrological, ecological, and economic impacts on these small islands. Specifically, dry conditions during the ERS are disproportionately related to the annual hydroclimatic outcome in this region (Miller et al. 2019a), meaning drought prediction efforts can be concentrated on a single season rather than the entire year. Recalling from section 1 , the question posed by this paper was "Could NWP models have successfully forecast the anomalously low GDI associated with the 2015 Caribbean drought?" Based on the evidence provided herein, the answer is a compelling "Yes." Though the purpose of this paper was not to develop a Puerto Rico drought early warning tool, it does provide a strong motivation for doing so.

The research presented here provides encouraging evidence for an added-value forecasting tool for ERS drought with as much as a 60-90-day lead time. In contrast, the 0-30-day CFS precipitation forecast preceding the initiation of the 2015 drought was unable to resolve the drying that would soon occur (Fig. 1c). Although the CFS GDI forecasts uniformly overpredict GDI (which taken at face value poorly predicted dry years), the predictions are significantly correlated with ERA5derived GDIs over the Caribbean with 0-30-day lead times and as well as radiosonde-derived GDI values from San Juan, PR (Fig. 7; $R^{2}=0.55 ; p=0.056$ ). Further, the GDI-based QPF tool outperforms climatology for lower-than-normal GDI environments, with clear statistical significance evident in the 0-30-day lead time window.

The CFS GDI forecasts presented here are a firststep toward an advanced warning decision-making aid. However, several issues exposed within this analysis need to be addressed before such a product could be operationalized. For instance, the CFS high-GDI bias was addressed in the QPF analysis when CFS GDIs were calibrated against TJSJ-derived GDIs; however, ideally, no such calibration would be necessary. More work should explore the origin of the high-GDI bias as well as its peculiar intensification as the lead time decreases. Further, the GDI's subcomponents were not forecast with uniform accuracy. Though not shown, the CFS's predictive skill was disproportionately tied to its accurate prediction of the CBI while it comparatively struggled to resolve the II and MWI. Future research should more thoroughly analyze the CFS's accuracy among the GDI's subcomponents with the aim of potentially restructuring the GDI, so that it is more robust to systematic NWP errors.

Last, the GDI-QPF relationship for Puerto Rico employed in section 3 was facilitated by previous GDIbased hydroclimate work for that region. The GDI likely possess statistically significant precipitation forecasting skill in other eastern Caribbean locations; however, the lack of existing empirical GDI-precipitation relationships in these areas prevent a broader validation of the CFS's drought detection capability. Future work should examine the extensibility of GDI-based QPF tools beyond Puerto Rico.

Acknowledgments. The authors acknowledge the assistance of Lexi Nelson in preparing the manuscript as well as the helpful feedback from three anonymous reviewers that improved the quality of the analysis herein.

\section{REFERENCES}

Carbin, G. W., M. K. Tippett, S. P. Lillo, and H. E. Brooks, 2016: Visualizing long-range severe thunderstorm environment guidance from CFSv2. Bull. Amer. Meteor. Soc., 97, 10211031, https://doi.org/10.1175/BAMS-D-14-00136.1.

DeFlorio, M. J., I. D. Goodwin, D. R. Cayan, A. J. Miller, S. J. Ghan, D. W. Pierce, L. M. Russell, and B. Singh, 2016: Interannual modulation of subtropical Atlantic boreal summer dust variability by ENSO. Climate Dyn., 46, 585-599, https://doi.org/10.1007/s00382-015-2600-7.

Durre, I., R. S. Vose, and D. B. Wuertz, 2006: Overview of the integrated global radiosonde archive. J. Climate, 19, 53-68, https://doi.org/10.1175/JCLI3594.1. 
European Centre for Medium-Range Weather Forecasts, 2017: ERA5 Reanalysis. Research Data Archive at the National Center for Atmospheric Research, Computational and Information Systems Laboratory, accessed 5 February 2019, https://doi.org/10.5065/D6X34W69.

Gálvez, J. M., and M. Davison, 2016: The Gálvez-Davison Index for tropical convection. 23 pp., accessed 27 February 2018, http://www.wpc.ncep.noaa.gov/international/gdi/ GDI_Manuscript_V20161021.pdf.

Hosannah, N., J. E. González, C. Lunger, and D. Niyogi, 2019: Impacts of local convective processes on rain on the Caribbean Island of Puerto Rico. J. Geophys. Res. Atmos., 124, 60096026, https://doi.org/10.1029/2018JD029825.

Kim, H.-M., P. J. Webster, and J. A. Curry, 2012: Seasonal prediction skill of ECMWF System 4 and NCEP CFSv2 retrospective forecast for the Northern Hemisphere winter. Climate Dyn., 39, 2957-2973, https://doi.org/10.1007/s00382012-1364-6.

Lepore, C., M. K. Tippett, and J. T. Allen, 2018: CFSv2 monthly forecasts of tornado and hail activity. Wea. Forecasting, 33, 1283-1297, https://doi.org/10.1175/WAF-D-18-0054.1.

McKee, T. B., N. J. Doesken, and J. Kleist, 1993: The relationship of drought frequency and duration to time scales. Preprints, Eighth Conf. on Applied Climatology, Anaheim, CA, Amer. Meteor. Soc., 179-184.

Miller, P. W., T. L. Mote, and C. A. Ramseyer, 2019a: An empirical study of the relationship between seasonal precipitation and thermodynamic environment in Puerto Rico. Wea. Forecasting, 34, 277-288, https://doi.org/10.1175/WAFD-18-0127.1.

— A. Kumar, T. L. Mote, F. D. S. Moraes, and D. R. Mishra, 2019b: Persistent hydrological consequences of Hurricane Maria in Puerto Rico. Geophys. Res. Lett., 46, 1413-1422, https://doi.org/10.1029/2018GL081591.

Mote, T. L., C. A. Ramseyer, and P. W. Miller, 2017: The Saharan air layer as an early rainfall season suppressant in the eastern Caribbean: The 2015 Puerto Rico drought. J. Geophys. Res. Atmos., 122, $10966-10$ 982, https://doi.org/ 10.1002/2017JD026911.

NOAA/NCEI, 2016: State of the climate: Drought for annual 2015. Accessed 13 November 2019, https://www.ncdc.noaa.gov/sotc/ drought $/ 201513$.

O'Connell, C. S., L. Ruan, and W. L. Silver, 2018: Drought drives rapid shifts in tropical rainforest soil biogeochemistry and greenhouse gas emissions. Nat. Commun., 9, 1348, https:// doi.org/10.1038/s41467-018-03352-3.

Ramírez, A., P. E. Gutiérrez-Fonseca, S. P. Kelly, A. C. Engman, K. Wagner, K. G. Rosas, and N. Rodríguez, 2018: Drought facilitates species invasions in an urban stream: Results from a long-term study of tropical island fish assemblage structure. Front. Ecol. Evol., 6, 115, https://doi.org/10.3389/ fevo.2018.00115.

Ramseyer, C. A., P. W. Miller, and T. L. Mote, 2019: Future precipitation variability during the early rainfall season in the El Yunque National Forest. Sci. Total Environ., 661, 326-336, https://doi.org/10.1016/j.scitotenv.2019.01.167.

Rosenfeld, D., and G. Gutman, 1994: Retrieving microphysical properties near the tops of potential rain clouds by multispectral analysis of AVHRR data. Atmos. Res., 34, 259-283, https://doi.org/10.1016/0169-8095(94)90096-5.

Saha, S., and Coauthors, 2014: The NCEP Climate Forecast System version 2. J. Climate, 27, 2185-2208, https://doi.org/10.1175/ JCLI-D-12-00823.1.

Svoboda, M., and Coauthors, 2002: The Drought Monitor. Bull. Amer. Meteor. Soc., 83, 1181-1190, https://doi.org/10.1175/ 1520-0477-83.8.1181.

Thornton, P. E., M. M. Thornton, B. W. Mayer, Y. Wei, R. Devarakonda, R. S. Vose, and R. B. Cook, 2017: Daymet: Daily surface weather data on a 1-km grid for North America, version 3. Oak Ridge National Laboratory Distributed Active Archive Center, accessed 15 November 2019, https://doi.org/ 10.3334/ORNLDAAC/1328.

Tian, D., E. F. Wood, and X. Yuan, 2017: CFSv2-based subseasonal precipitation and temperature forecast skill over the contiguous United States. Hydrol. Earth Syst. Sci., 21, 14771490, https://doi.org/10.5194/hess-21-1477-2017.

Torres-Valcárcel, A. R., 2018: Teleconnections between ENSO and rainfall and drought in Puerto Rico. Int. J. Climatol., 38, e1190-e1204, https://doi.org/10.1002/joc.5444.

Wang, W., 2016: Assessment of the CFSv2 real-time seasonal forecasts for 2015. Accessed 10 October 2019, http://www. cpc.ncep.noaa.gov/products/people/wwang/cfs_assessment/ CFS_fcst_2015_web.ppt.

—, M. Chen, and A. Kumar, 2015: Assessment of the CFSv2 realtime seasonal forecasts for 2014. Accessed 10 October 2019, http:/ www.cpc.ncep.noaa.gov/products/people/wwang/cfs_assessment/ CFS_fcst_2014_web.ppt.

Yu, H., and Coauthors, 2006: A review of measurement-based assessments of the aerosol direct radiative effect and forcing. Atmos. Chem. Phys., 6, 613-666, https://doi.org/10.5194/acp-6613-2006.

Yuan, X., and E. F. Wood, 2013: Multimodel seasonal forecasting of global drought onset. Geophys. Res. Lett., 40, 4900-4905, https://doi.org/10.1002/grl.50949.

Zuidema, P., C. Alvarez, S. J. Kramer, L. Custals, M. Izaguirre, P. Sealy, J. M. Prospero, and E. Blades, 2019: Is summer African dust arriving earlier to Barbados? The updated long-term in situ dust mass concentration time series from Ragged Point, Barbados, and Miami, Florida. Bull. Amer. Meteor. Soc., 100, 1981-1986, https://doi.org/10.1175/BAMS-D-18-0083.1. 